\title{
Magic Mouthwash
}

National Cancer Institute

\section{Source}

National Cancer Institute. Magic Mouthwash. NCI Thesaurus. Code C29238.

A combination preparation of mouth rinsing suspension containing an antacid, an antihistamine and an anesthetic agent. Usually, magic mouthwash consists of lidocaine for its anesthetic activity, the antihistamine diphenhydramine and the antacids aluminum hydroxide and/or magnesium hydroxide. Sucralfate, an anti-ulcer agent, can be added to the mouthwash to form a protective coating over the lesion areas by binding to the proteins at the inflamed mucous lining. In addition, the antimycotic agent nystatin is often added to stop fungal growth. Magic mouthwash is used to treat chemotherapyand/or radiation-induced oral mucositis. 